\title{
Las partes de la oración en Isidoro de Sevilla
}

\author{
Luis Alberto HERnANDo CUADRADO \\ Universidad Complutense de Madrid \\ lahernan@ucm.es
}

Recibido: 29 de enero de 2013

Aceptado: 14 de octubre de 2013

\section{RESUMEN}

El objeto de este artículo, como se indica en el título, es el estudio de las partes de la oración en Isidoro de Sevilla. Tras exponer los aspectos relacionados con las Etimologiae, la gramática, la oración y las partes de la oración en la introducción, el autor se centra a continuación en la doctrina del nombre, el pronombre y el verbo, las partes más complejas. Posteriormente aborda la naturaleza de las restantes partes (adverbio, participio, conjunción, preposición e interjección). En todo momento sitúa los puntos de vista tomados en consideración en el contexto de la tradición gramatical. En las citas respeta las grafías de los textos originales.

Palabras clave: Isidoro de Sevilla. Etymologiae. Gramática. Partes de la oración.

Hernando Cuadrado, L.A., «Las partes de la oración en Isidoro de Sevilla», Cuad. Fil. Clás. Estud. Lat. 33.2 (2013) 281-301.

\section{The parts of speech in Isidore of Seville}

\begin{abstract}
The purpose of this article, as it is indicated by its title, is the study of the parts of the speech in Isidore of Seville. After expounding the aspects related to the Etimologiae, the grammar, the sentence and the parts of speech in the introduction, the author then focuses on the doctrine of the noun, the pronoun and the verb, the more complex parts. Subsequently he discusses the nature of the remaining parts (adverb, participle, conjunction, preposition and interjection). At any moment he places the points of view taken into consideration in the context of the grammatical tradition. In the quotes he maintains the graphies of the original texts.
\end{abstract}

Keywords: Isidore of Seville. Etymologiae. Grammar. Parts of speech.

Hernando Cuadrado, L.A., «The parts of speech in Isidore of Seville», Cuad. Fil. Clás. Estud. Lat. 33.2 (2013) 281-301.

Sumario 1. Introducción. 2. El nombre. 3. El pronombre. 4. El verbo. 5. Otras partes. 6. Conclusiones. 7. Referencias bibliográficas. 


\section{INTRODUCCIÓN}

1.1. La figura de Isidoro de Sevilla (¿Cartagena, 560? - Sevilla, 636) suele aparecer vinculada a las Etymologiae, compuestas en plena madurez, donde condensa y sistematiza todo el conocimiento de su tiempo. En el primer libro de esta magna obra se descubre una faceta suya, la de gramático, poco tenida en cuenta en la investigación especializada, pero no por ello carente de valor e interés ${ }^{1}$. En el presente artículo nos proponemos analizar su posicionamiento doctrinal en el tratamiento de las partes de la oración a la luz del contexto de la tradición gramatical.

Las Etymologiae, tituladas también Etymologiarum sive originum libri $X X^{2}$, la aportación más conocida de Isidoro de Sevilla, es una enciclopedia monumental que refleja la evolución del conocimiento desde la antigüedad pagana y cristiana hasta el siglo VII. El texto, que alcanzó una gran difusión en las bibliotecas europeas de la época carolingia y sirvió de base a los maestros de la escolástica, si bien sigue la estructura de las Institutiones divinarum et saecularium litterarum de Casiodoro, a partir del libro $\mathrm{V}$ se convierte en repertorio lexicográfico con esquemas análogos a los utilizados en el siglo II por Suetonio, en Pratum de rebus variis, y Aulo Gelio, en Noctes Atticae.

La obra, como reza en el segundo título anotado, se encuentra dividida en los veinte libros en que la distribuyera Braulio, a quien se la había enviado el autor para su corrección. Los tres primeros giran en torno a las disciplinas de las artes liberales, el trivium, los dos primeros, y el quadrivium, el tercero. El primero, como ya hemos apuntado, versa sobre la gramática; el segundo, sobre la retórica y la dialéctica; y el tercero, sobre las matemáticas, la aritmética, la geometría, la música y la astronomía ${ }^{3}$.

El método empleado en las Etymologiae es el de la abreviación. Esta técnica, muy del gusto de su tiempo, constituye un procedimiento de vulgarización con el que se pretende reducir el saber a fórmulas concentradas, fácilmente memorizables. Practicada desde la época helenística, la abreviación se convierte en una auténtica obsesión en Isidoro de Sevilla hasta tal punto que, como advierte J. Fontaine, «il donne même l'impression d'avoir voulu excuser son activité littéraire en la situant explicitement dans le cadre traditionnel des compendia» $(1959, \mathrm{p} .766)$.

\footnotetext{
${ }^{1}$ Como advierte L. Holtz, «le De grammatica d'Isidore de Séville est comme l'introduction générale de l'encyclopédie isidorienne, puisque celle-ci est fondée sur une notion grammaticale, l'étymologie» (2006, p.55).

${ }^{2}$ Este segundo título es el que, como tendremos ocasión de comprobar, lleva la obra en la edición de W.M. Lindsay (1991), la que manejaremos principalmente en este trabajo.

${ }^{3}$ Los restantes libros tratan de la medicina, el cuarto; de las leyes y los tiempos, el quinto; de los libros y oficios eclesiásticos, el sexto; de Dios, los ángeles y los fieles, el séptimo; de la Iglesia y las sectas, el octavo; de las lenguas, pueblos, reinos, milicia, ciudades y parentescos, el noveno; de las palabras, el décimo; del hombre y los seres religiosos, el undécimo; de los animales, el duodécimo; del mundo y sus partes, el decimotercero; de la tierra y sus partes, el decimocuarto; de los edificios y los campos, el decimoquinto; de las piedras y los metales, el decimosexto; de la agricultura, el decimoséptimo; de la guerra y los juegos, el decimoctavo; de las naves, edificios y vestidos, el decimonoveno; y de las provisiones y de los utensilios domésticos y rústicos, el vigésimo.
} 
La ordenación de la materia no depende siempre de una estructuración racional y lógica, sino más bien del interés didáctico. En repetidas ocasiones se observa que el autor llega a un lema o a un capítulo inducido por la presencia en el contexto de algún término vinculado con el capítulo correspondiente, que suscita en él la necesidad de aclararlo o describirlo inmediatamente, encadenándose los temas con una ordenación que se percibe como laxa.

En la formulación etimológica isidoriana se distinguen, en mayor o menor grado, varias etapas, como la definición del concepto, el análisis del vocablo (en sí mismo, para descubrir su composición o derivación, o en relación con otros, sobre todo griegos), la explicación de sus vinculaciones con el referente y los modos de comprensión lingüística de este. En las dos últimas desempeña un papel de capital importancia el conocimiento de las realidades antiguas, pero la historia de una palabra y la del objeto designado son notas que subyacen en ellos ${ }^{4}$.

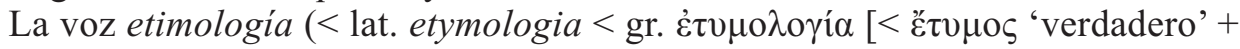

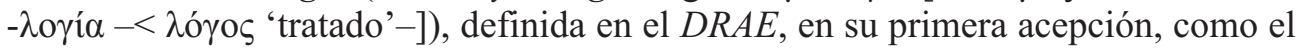
«origen de las palabras, razón de su existencia, de su significación y de su forma» (2001, s.v.), y en la segunda, como la «especialidad lingüística que estudia el origen de las palabras consideradas en dichos aspectos» $(2001$, s.v.), aparece documentada por primera vez en Dionisio de Halicarnaso (siglo I a.C.).

Sin embargo, la reflexión etimológica es mucho más antigua, ya que se encuentra unida a las especulaciones de los primeros filósofos sobre el origen del lenguaje y fue el centro de la controversia que enfrentó en la Edad Media a los analogistas y los anomalistas, si bien no posee estatuto propiamente científico hasta el siglo XIX con la gramática comparada. Actualmente, la ciencia etimológica toma en consideración la filiación de las formas y los sentidos sucesivos, las vicisitudes del empleo y los factores sociológicos del cambio.

Examinada desde la perspectiva científica, la etimología, en opinión de Isidoro de Sevilla, tiene como objeto de estudio el origen de los vocablos, ya que mediante su interpretación se llega a conocer el sentido de las palabras y los nombres (Etymologia est origo vocabulorum, cum vis verbi vel nominis per interpretationem colligitur [Lindsay 1991, I.XXIX.1]), y su conocimiento es muy útil en la interpretación, dado que, si se conoce el origen de una palabra, será más fácil comprender inmediatamente su sentido.

La etimología unas veces se descubre por la causa (reges ['reyes'] < regere ['regir'] < recte agere ['conducir rectamente']); otras, por el origen (homo ['hombre'] < humus ['tierra']); en ocasiones, por los contrarios (lutum ['lodo'] < lavare ['lavar']). Algunas proceden de una derivación nominal (prudens ['prudente'] < prudentia ['prudencia']); otras, del sonido (garrulus ['garrulo'] < garrulitas ['garrulería']). Las hay de origen griego que han pasado al latín (silva ['selva']). También existen palabras derivadas de nombres de lugares, ciudades o ríos. Incluso, muchas se remontan a lenguas de distintos pueblos.

${ }^{4}$ Las Etymologiae, en cualquier caso, como advierte M. Menéndez y Pelayo, «son un milagro de erudición para aquella edad, y ni Casiodoro, ni el Venerable Beda, ni Alcuino, ni Rabano Mauro las igualan» (Cossío 1959, p.23). 
1.2. La gramática, en la línea de los tratadistas latinos, es concebida por Isidoro de Sevilla como la ciencia que enseña a hablar correctamente, y el origen y fundamento de las letras liberales (scientia recte loquendi, et origo et fundamentum liberalium litterarum [Lindsay 1991, I.V.1]) $)^{5}$. Dentro del conjunto de las disciplinas se encuentra situada después de las letras comunes con vistas a que quienes ya las conocen puedan aprender las normas del bien hablar. El vocablo gramática, tomado de las letras, llamadas en griego $\gamma \rho \alpha ́ \mu \mu \alpha \tau \alpha$, teniendo en cuenta además que se basa en las reglas del arte y que muy probablemente este último vocablo deriva del griego

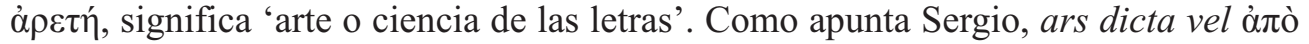
$\tau \tilde{\eta} \varsigma \grave{\alpha} \rho \varepsilon \tau \tilde{\eta} s$, id est a virtute, quam Graeci unius cuiusque rei scientiam vocant; vel certe ideo ars dicitur, quod artis praeceptis cuncta concludat (Keil 1981, IV, p.405).

En otro lugar, Isidoro de Sevilla caracteriza la gramática, en relación con las otras disciplinas del trivium, la retórica -que por la elegancia y los recursos propios de la elocuencia es considerada sumamente imprescindible en los asuntos civiles (propter nitorem et copiam eloquentiae suae maxime in civibus quaestionibus necessaria existimatur [Lindsay 1991, I.II.1)-y la dialéctica -también denominada lógica, que con los más sutiles argumentos separa lo verdadero de lo falso (cognomento logica, quae disputationibus subtilissimis vera secernit a falsis [Lindsay 1991, I.II.1])-, como la habilidad en el hablar (loquendi peritia [Lindsay 1991, I.II.1]).

En el mundo griego, Dionisio de Tracia había concebido la gramática como la práctica obtenida de la lectura de los poetas y prosistas, es decir, la disciplina, equivalente a

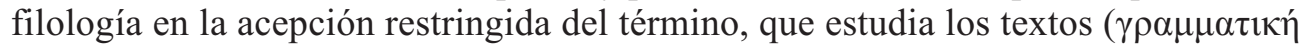

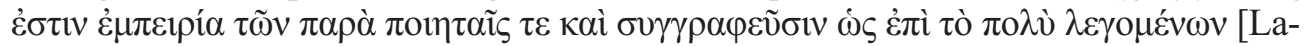
llot 1989, p.40]). Esta idea encontró eco en los autores latinos, que la reprodujeron con algunas matizaciones. Mario Victorino, que en un principio había apuntado: ut Varroni placet, ars grammatica scientia est eorum, quae a poetis, historicis oratoribusque dicuntur ex parte maiore (Uhlig 1965, I, p.5), después explica que consiste en el intellectu poetarum et recte loquendi scribendique ratione (Keil 1981, VI, p.4); Sergio señala de la gramática: consistit in intellectu poetarum et in recte scribendi loquendive ratione (Keil 1981, IV, p.486); y Máximo Victorino concluye igualmente que es la scientia interpretandi poetas atque historicos et recte scribendi, loquendique ratio (Keil 1981, VI, p.188).

Enlazando con esta tradición, la gramática es definida por Nebrija en las Introducciones como la scientia recte loquendi recteque scribendi ex doctissimorum uirorum usu atque auctoritate collecta (1525, fol.XLII). F. Sánchez de las Brozas, del mismo modo que Isidoro de Sevilla, la interpreta como el arte de hablar correctamente (ars recte loquendi [Sánchez Salor - Chaparro Gómez 1995, p.46]), sin mencionar la escritura, como más tarde hará, por ejemplo, A. Bello, quien escribe que «la GRAMÁTICA de una lengua es el arte de hablarla correctamente, esto es, conforme al buen uso, que es el de la gente educada» (Trujillo 1988, p.165). En la última impresión de la GRAE, igual que en numerosos manuales del siglo $\mathrm{XX}$, aún se enseña que «Gramática es el arte de hablar y escribir correctamente» $(1962$, p.7).

\footnotetext{
${ }^{5}$ J. Oroz Reta y M.A. Marcos Casquero anotan que en otras ediciones más antiguas de las Etimologiae se añade scribendique ratio (1982, p.284, n.17).
} 
1.3. La oración, en el contexto de la tradición grecolatina, es concebida por el arzobispo hispalense con un criterio semántico como una sucesión de palabras con sentido (contextus verborum cum sensu [Lindsay 1991, I.V.3]), de manera que cualquier sucesión de palabras carente de sentido no es oración, dado que esta, para ser completa, ha de serlo a la vez por el sentido, la voz y la letra.

Con el mismo criterio semántico, Dionisio de Tracia había definido esta unidad lingüística como una unión de palabras que representan un sentido completo ( $\lambda$ ó

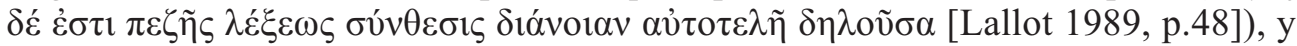
Prisciano corrobora que oratio est ordinatio dictionum congrua sententiam perfectam demonstrans (Keil 1981, II, p.53). Las expresiones de esta índole son las que más se han repetido a lo largo del tiempo. Las encontramos, por ejemplo, en A. Alonso P. Henríquez Ureña («la menor unidad del habla con sentido completo» [1971, p.10]), el Esbozo («unidades de sentido completo» [1973, p.349]) o el DRAE («Palabra o conjunto de palabras con que se expresa un sentido gramatical completo» [2001, s.v.]).

Basándose en la etimología, Carisio sostiene: oratio est ore missa et per dictiones ordinata pronuntiatio, ut oris ratio (Keil 1981, I, p.152); Pompeyo apunta: oratio dicitur elocutio, et dicta oratio quasi oris ratio (Keil 1981, V, p.96); y Sergio ratifica: oratio dicitur elocutio, quasi oris ratio (Keil 1981, IV, p.487). Nebrija en las Introducciones define la oración: ut Scaurus deffinit, ore missa et per dictiones ordinata pronuntiatio (1525, fol.LVIIIv.), donde, como se ve, reproduce las palabras de Carisio omitiendo la última parte.

El arte gramatical, en consonancia con la tendencia de la época a interpretar los diferentes tipos de fenómenos lingüísticos y literarios como partes integrantes de ella, es dividida por Isidoro de Sevilla en treinta apartados, desglosados en las ocho partes de la oración, más la pronunciación, la letra, la sílaba, los pies, el acento, la puntuación, las características, la ortografía, la analogía, la etimología, las glosas, las diferencias, los barbarismos, los solecismos, los vicios, los metaplasmos, los esquemas, los tropos, la prosa, los metros, las fábulas y las historias.

Isidoro de Sevilla cuenta en este punto con seguidores como Alcuino, Elfrico y Hugo de San Víctor, quienes, como es lógico, presentan algunas variantes con respecto a él. Sin embargo, pronto se impondría la estructuración de la gramática en las cuatro partes que distingue Nebrija (ortografía, prosodia, etimología y sintaxis), que se centran, respectivamente, en el estudio de la letra, sílaba, palabra y construcción, las mismas que, con el cambio del nombre de la tercera de ellas por el de analogía efectuado por el P. B. de San Pedro en 1769, había reconocido la GRAE desde la edición de 1796 e incorporado desde la de1870 como la mayor parte de las gramáticas de nuestra tradición.

1.4. Ante la disparidad de criterio en relación con el número de partes de la ora-

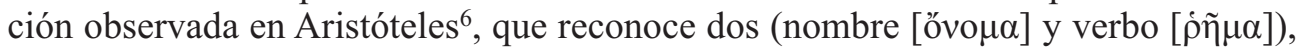

\footnotetext{
${ }^{6}$ Hoy sabemos que el primero que distingue las dos partes de la oración indicadas es Platón. Aristóteles

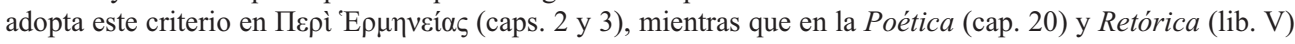
reconoce una tercera, denominada $\sigma 0 ́ v \delta \varepsilon \sigma \mu \rho \varsigma$, que comprende la conjunción, la preposición, el artículo y el pronombre (Robins 1992, pp.43-45 y 60-61).
} 
y en Donato, que distingue ocho (nombre, pronombre, verbo, participio, preposición, adverbio, interjección, conjunción), el autor de las Etymologiae considera que todas ellas se reducen en última instancia a las dos propuestas por el filósofo griego, que son las principales, y expresan, respectivamente, la persona y la acción.

Las restantes partes de la oración, a su juicio, son meros apéndices de ellas. El pronombre deriva del nombre y desempeña su oficio, el adverbio también procede del nombre, y el participio participa de la naturaleza del nombre y del verbo. Dado que la conjunción, la preposición y la interjección, que actúan dentro del campo de acción de estas, prácticamente son superfluas, se puede aceptar, como defienden algunos gramáticos, que solamente existen cinco (nombre, pronombre, verbo, participio, adverbio).

En este sentido, Prisciano hace referencia al sistema de cinco partes de la oración de los estoicos (Secundum Stoicos vero quinque sunt eius partes: nomen, appellatio, verbum, pronomen sive articulus, coniunctio [Keil 1981, II, p.54]) ${ }^{7}$. Por su parte, Varrón sostiene:

quoius quoniam sunt divisiones plures, nunc ponam potissimum eam qua dividitur oratio secundum naturam in quattuor partis: in eam quae habet casus et quae habet tempora et quae habet neutrum et in qua est utrumque. Has vocant quidam appellandi, dicendi, adminiculandi, iungendi (1990, p.316).

F. Sánchez de las Brozas, con el precedente de B. de Busto y C. de Villalón, rebaja el número de partes de la oración a tres, el nombre, que comprende las entidades de tipo estático, y el verbo, que abarca las de tipo dinámico, a las que añade las partículas. En esta interpretación lógica y racionalista, el grupo de las partículas se halla integrado por la preposición, el adverbio y la conjunción; el pronombre se encuentra incluido en la categoría del nombre (sustantivo o adjetivo); el participio es un nombre adjetivo que toma del verbo de que proviene su significación y régimen de construcción; y las interjecciones, debido a su naturaleza de sonidos inarticulados y naturales, no pueden ser partes de la oración.

El sistema de ocho partes es el seguido por la mayoría de los gramáticos latinos. Nebrija, que lo propone en un principio en las Introductiones, posteriormente considera que tanto el gerundio como el supino poseen entidad suficiente como para constituir partes de la oración independientes, con lo que acaba reconociendo diez en dicha obra como en la Gramática (donde excluye la interjección, incorpora el artículo y el nombre participial infinito, y mantiene el gerundio).

En la GRAE, habiéndose reconocido nueve en la edición de 1771 -las ocho de Dionisio de Tracia (entre las que no figura la interjección, pero sí el artículo) y la mayoría de los gramáticos latinos (en cuya lengua no existe el artículo, y la interjección, sin embargo, es parte de la oración)-, desde la de 1870 su número se eleva a diez al ser

\footnotetext{
${ }^{7}$ En realidad, los estoicos propusieron tres clasificaciones; en la primera distinguen cuatro partes (ővo $\mu \alpha$, $\dot{\rho} \tilde{\eta} \mu \alpha, \sigma u ́ v \delta \varepsilon \sigma \mu \mathrm{s}, \alpha \not \alpha \theta \rho o v)$, al separar de la tercera reconocida por Aristóteles en la Poética y Retórica los miembros con flexión (å $\rho \theta \rho o v)$; en la segunda, cinco, al dividir el nombre de Platón y Aristóteles en el nombre propio (ővo $\mu \alpha)$ y el nombre común $(\pi \rho \circ \sigma \eta \gamma o \rho i ́ \alpha)$; y en la tercera, seis, al desgajar el adverbio $(\mu \varepsilon \sigma o ́ \tau \eta \varsigma)$ del nombre común.
} 
interpretados el sustantivo y el adjetivo como dos categorías independientes, y, una vez eliminado en la de 1916 el participio, pasando a ser considerado una forma del verbo más - de acuerdo con la tendencia introducida en nuestro país por G.M. de Jovellanos en 1795 bajo la influencia de los gramáticos filósofos franceses-, en la de 1917, del mismo modo que en la mayor parte de los textos gramaticales, vuelven a registrarse nueve.

\section{EL NOMBRE}

2.1. El nombre, que en latín viene a equivaler a notamen 'medio de designación', recibe esta denominación porque con su indicación nos permite conocer las cosas ( $\mathrm{No}$ men dictum quasi notamen, quod nobis vocabulo suo res notas efficiat [Lindsay 1991, I.VII.1]). En su tratamiento en las Etymologiae, a continuación de esta caracterización, sin una enumeración previa de sus accidentes como suelen hacer los gramáticos grecolatinos, se establece una clasificación en la que se encuentran incluidos los elementos y fenómenos que guardan relación con la cualidad y la especie, y después se estudian la comparación, el género, el número y el caso, aludiéndose muy brevemente a la figura.

Sobre la etimología del término nomen, Diomedes explica: nomen autem dicitur, quod unam quamque rem monstret ac notet, quasi notamen media syllaba per sinco-

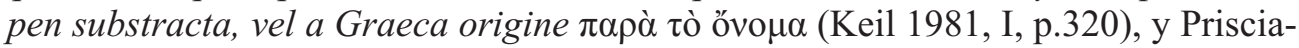
no comenta: dicitur autem nomen vel a Graeco, quod est vó $\mu \alpha$ et adiecta o övo $\mu \alpha$, dictum a tribuendo, quod vé $\mu \varepsilon \mathrm{v}$ dicunt, vel, ut alii, nomen quasi a notamen, quod hoc notamus uniuscuiusque substantiae qualitatem (Keil 1981, II, p.57). J. Oroz Reta y M.A. Marcos Casquero, además de confirmar el parentesco entre nomen y ónoma (1982, p.286, n.18), señalan que «otros relacionan noscimen y nomen, como noscibilis y nobilis» (1982, p.286, n.18).

2.2. Isidoro de Sevilla distribuye los nombres en primer lugar en dos grupos, el de los propios, los privativos de una persona determinada a la que designan, y el de los apelativos, los comunes a muchos, distinguiendo entre los nombres propios cuatro clases, llamadas, respectivamente, prenombre, por colocarse delante del nombre (Lucius); nombre, por designar a la familia (Cornelius); cognombre, por ir unido al nombre (Scipio); y agnombre, de origen extrínseco, impuesto por algún motivo (Creticus).

La clasificación de los nombres propios es una cuestión que había solido ser tratada por los gramáticos latinos. Carisio, por ejemplo, afirma de los nombres propios:

in species quattuor dividuntur, praenomen, nomen, cognomen, agnomen, ut Pupilius Cornelius Scipio Africanus. Nam agnomina cognominibus ex aliqua ratione aut virtute adduntur, velut Africanus, Creticus, Asiaticus, Numantinus et his similia, praenomen ergo est quod nomini praeponitur, ut Publius, nomen quod familiae originem declarat, ut Cornelius, cognomen quod nomini subiungitur, ut Scipio, agnomen extrinsecus adici solet, ut Africanus (Keil 1981, I, pp.152-153). 
Los nombres apelativos son divididos en las Etymologiae en veintiocho clases ${ }^{8}$, entre las que, como se puede comprobar por la relación exhaustiva presentada en la nota, además de los comprendidos dentro del accidente de la especie, se encuentra la de los epítetos o adjetivos, llamados de esta manera por colocarse junto al nombre para completar su significado (Epitheta, quae Latine adiectiva vel superposita appellantur, eo quod ad inplendam sui significationem nominibus adiciantur, ut magnus, doctus. Adicis ea personis, ut magnus philosophus, doctus homo, et plenus est sensus [Lindsay 1991, I.VII.22]), y, como se ha indicado anteriormente, no deslindados de la categoría del sustantivo para constituir dos partes independientes de la oración.

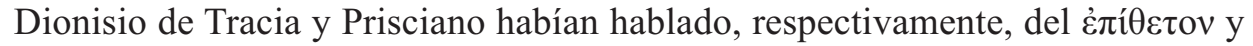
adiectivum con el significado de adjetivo ornamental más bien. En palabras de Prisciano, adiectivum est quod adicitur propriis vel appellativis et significat laudem vel vituperationem vel medium vel accidens unicuique (Keil 1981, II, p.60). Nebrija, en las Introductiones, basa la diferencia entre el sustantivo y el adjetivo, desde el punto de vista morfosintáctico, en que aquel est quod declinat per unum articulum vel per duos tantum (1525, fol.XV) y este, quod declinat per tres artículos vel per tres diversas terminationes $(1525$, fol.XV), $\mathrm{y}$, desde la perspectiva semántica, en que el primero es quod substantiam significat (1525, fol.XLVv.), mientras que el último, quod adiectum substantivo significat in eo aliquid accidens (1525, fol.XLVv.).

2.3. En la comparación, que recibe este nombre debido a que, al ser parangonadas dos cosas, se da preferencia a una de ellas sobre la otra (ex alterius conparatione alterum praeferit [Lindsay 1991, I.VII.27]), se distinguen tres grados, el positivo, que se pone como punto de referencia en la gradación (primus ponitur in conparationis gradu [Lindsay 1991, I.VII.27]) (doctus ['docto']); el comparativo, que, comparado con el positivo, es preferido a él (conparatus positivo praeferitur illi [Lindsay 1991, I.VII.27]) (doctior ['más docto']); y el superlativo, que sobrepasa al comparativo (conparativo superferatur [Lindsay 1991, I.VII.27]) (doctissimus ['doctísimo']).

La comparación, como se ha indicado, es considerada accidente por Donato, Probo y Consentio. Donato explica: conparationis gradus sunt tres, positivus, conparativus, superlativus: positivus, $u t$ fortis; conparativus, ut fortior; superlativus, $u t$ fortissimus (Keil 1981, IV, p.374). Sin embargo, Dionisio de Tracia, Diomedes y Prisciano tratan el comparativo y el superlativo como clases de nombres derivados en el accidente de la especie. Nebrija sigue el esquema de Prisciano.

\footnotetext{
${ }^{8}$ Los nombres apelativos pueden ser corporales, incorporales, generales, especiales, principales, derivados, diminutivos, diminutivos por el sonido pero principales por el significado, completamente griegos, completamente latinos, intermedios, bastardos, sinónimos, homónimos, relativos, cuasi relativos, cualitativos, cuantitativos, patronímicos, ctéticos, epítetos, actuales, gentilicios, patrios, locales, verbales, participiales, similiverbales. La denominación de las dos clases fundamentales de nombres por la especie, como en Diomedes y Prisciano, que siguen a su vez a Dionisio de Tracia, quien señala que existen dos especies, primitiva y derivada, es principales y derivados, mientras que Nebrija utilizará en las Introductiones los términos primitiva y derivativa (primitiva, quae aliunde non trahitur, ut mons. Derivativa, quae aliunde derivantur, ut montanus $a$ monte [1525, fol.XLVI]).
} 
2.4. Los géneros, que se llaman así porque generan (quod generent [Lindsay 1991, I.VII.28]), en realidad, son solo dos, el masculino y el femenino, por lo que los restantes tipos que se suelen reconocer debido al prestigio de los gramáticos que han hablado de ellos (neutro, común, epiceno, universal) no son géneros. En esta línea se encuentran situados los gramáticos latinos Consentio y Prisciano, quien explica: genera igitur nominum principalia sunt duo, quae sola novit ratio naturae, masculinum et femininum. Genera enim dicuntur a generando proprie quae generare possunt, quae sunt masculinum et femininum (Keil 1981, II, p.141), y, después de Isidoro de Sevilla, F. Sánchez de las Brozas, el cual corrobora: que genera duo ese dicimus, quae sola nouit ratio naturae, nam quia per mares et foeminas propagarentur genera, genus dictum fuit, et lingua chaldaea, hebraea, syra, punica, hispana, gallica, italica et aliae plures duo tantum agnoscunt genera (Sánchez Salor - Chaparro Gómez 1995, p.66).

2.5. Por medio del número, según Isidoro de Sevilla, se indica si los nombres están en singular o en plural. Dos son, asimismo, los números reconocidos por algunos gramáticos latinos, como Carisio o Prisciano, que rechazan el dual, admitido por otros. El primero manifiesta: numeri sunt duo, singularis et pluralis; dualis enim apud Romanos non est (Keil 1981, I, p.18), y el segundo confirma: est autem vel singularis vel pluralis, nam dualis apud Latinos non invenitur (Keil 1981, II, p.172). Los números, para Nebrija en las Introductiones, son igualmente duo: singularis, qui unum significat, ut homo. Pluralis, qui plura, ut homines (1525, fol. XLVIIIv.). F. Sánchez de las Brozas concluye: numerus alius singularis, alius pluralis, neque plures numeri fuerunt necessarii (Sánchez Salor - Chaparro Gómez 1995, p.58).

2.6. Por la figura -accidente que, como se ha comentado antes, el autor menciona aquí-, se distingue si son simples o compuestos. Isidoro de Sevilla, como Donato, Probo y Consentio, y más tarde Nebrija, reconoce dos clases de nombres por la figura (figura). Donato había afirmado: figurae nominibus accidunt duae, simplex et conposita: simplex, ut doctus, potens; conposita, ut indoctus, impotens (Keil 1981, IV, p.377). Nebrija ratifica en las Introductiones que las figuras son dos: simplex, quae non potest dividi in partes significativas eius quod integrum significat, ut parens. Composita, quae potest dividi in partes significativas eius quod ante compositionem significabant, ut parricida (1525, fol.XLVIIIv.).

2.7. Los casos, mediante los cuales las palabras flexionadas muestran variaciones y caen (per eos enim inflexa nomina variantur et cadunt [Lindsay 1991, I.VII.31]), son seis, el nominativo, por el que nombramos algo (per eum aliquid nominamus [Lindsay 1991, I.VI.31]); genitivo, por el que indagamos la ascendencia de alguien (per eum genus cuiuscumque quaerimus [Lindsay 1991, I.VII.31]); dativo, por el que manifestamos que algo se da a alguien (per eum nos dare alicui aliquid demonstramus [Lindsay 1991, I.VII.32]); acusativo, por el que «acusamos» a alguien (per eum aliquem accusamus [Lindsay 1991, I.VII.32]); vocativo, por el que llamamos a alguien (per eum aliquem vocamus [Lindsay 1991, I.VII.32]); y ablativo, por el que indica- 
mos que algo le es quitado a alguien (per eum nos auferre aliquid cuiquam significamus [Lindsay 1991, I.VII.32]) 9 .

\section{EL PRONOMBRE}

3.1. El pronombre recibe esta denominación porque se pone en lugar del nombre para evitar, como aconseja Sergio, la pesadez que produce su repetición (Pronomen dictum, quia pro vice nominis ponitur, ne fastidium faciat nomen ipsud dum iteratur [Lindsay 1991, I.VIII.1]). De esta manera, cuando se dice: Vergilius scripsit Bucoli$c a$, se puede añadir luego, empleando un pronombre, Ipse scripsit Georgica, con lo que la variedad léxica evita la pesadez y comporta elegancia estilística.

Desde que Dionisio de Tracia lo concibiera como la palabra usada en lugar del

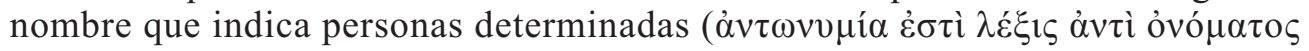

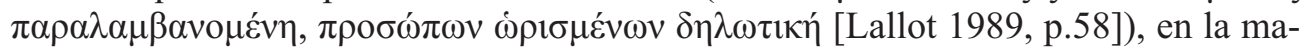
yor parte de los tratados de la tradición gramatical el pronombre ha sido considerado como un sustituto. Para los latinos Donato, Carisio, Diomedes y Probo, este aspecto es fundamental. Prisciano, basándose en Apolonio Díscolo, lo considera como un sustituto del nombre propio solamente. Nebrija, influido por Prisciano, lo presenta como pars orationis declinabilis quae pro nomine proprio cuiusque accipitur, personasque finitas recipit (1525, fol.XLIX).

Sergio, en efecto, había observado: totiens dicere Virgilius scripsit Bucolica, Virgilius scripsit Georgica, Virgilius scripsit Aeneidos odiosum est, cum possis variare, ut dicas Virgilius scripsit Bucolica, idem Georgica, ipse Aeneidos (Keil 1981, IV, p.499). La huella de Sergio e Isidoro de Sevilla se manifiesta principalmente bajo las variantes de «la palabra que se pone en lugar del nombre para evitar su repetición» (Grammaire de Port-Royal, B. de San Pedro, GRAE [desde la edición de 1796 hasta la de 1916]), y «la palabra que se pone en lugar del nombre para evitar su repetición y representa las personas que intervienen en el discurso» (Mata, Sánchez Doblas y Arañó).

3.2. Los pronombres son clasificados, en primer lugar, como hacen los gramáticos grecolatinos por el accidente de la cualidad, en determinados, los que determinan a una persona precisa (definiunt certam personam [Lindsay 1991, I.VIII.2]) (ego); indeterminados, los que no especifican una persona concreta (non sunt certae personae [Lindsay 1991, I.VIII.2]) (quis ['alguien'], quae ['alguna'], quod ['algo']); y semideterminados, los que mencionan a una persona conocida (commemorationem faciunt notae personae [Lindsay 1991, I.VIII.2]) (ipse, iste). Isidoro de Sevilla sigue muy de cerca en este punto a los gramáticos latinos, especialmente a Donato, Dio-

\footnotetext{
${ }^{9}$ Siguiendo a Prisciano, para quien sunt igitur formae casuales sex (Keil 1981, II, p. 187), señala Isidoro de Sevilla que los nombres que presentan variantes en los seis casos (unus) son exaptotos; los que las presentan en cinco (doctus), pentaptotos; los que en cuatro (lateris), tetraptotos; los que en tres (templum), triptotos; los que en dos (Iuppiter), diptotos; y los que en uno (frugi), monoptotos. Esta clasificación es adoptada por Nebrija al hablar de las maneras de la declinación de los nombres.
} 
medes y Prisciano. Diomedes, por ejemplo, afirma de la cualidad de los nombres: finita est quae notat certum numerum et gestum dirigit ad certam personam, ut ego. Infinita est quae certam non recipit personam sed cuilibet potest aptari, ut quis, quae, quod. Minus quam finita est quae certis et incertis personis aptari potest, ut ipse (Keil 1981, I, p.329).

En segundo lugar, de acuerdo con Carisio y Diomedes principalmente, los pronombres se dividen en posesivos, los que indican que se posee algo (aliquid nos possidere ostendunt [Lindsay 1991, I.VIII.3]) (meus, tuus ); relativos, los que se refieren a una interrogación (ad interrogationem referuntur [Lindsay 1991, I.VIII.3]), como cuando se dice quis est? ('¿quién es?') y se responde is est ('ese es'); y demostrativos, los que muestran algo sin acompañar a un nombre (habent demonstrandi significationem [Lindsay 1991, I.VIII.3]) (hic, haec, hoc), y artículos, estos mismos elementos articulados o unidos con los nombres (nominibus artantur, id est conligantur [Lindsay 1991, I.VIII.4]) (hic orator; hic sapiens).

Por último, los pronombres, del mismo modo que en las clasificaciones de los gramáticos grecolatinos por el accidente de la especie, son primitivos o derivados. Los primitivos, los que no tienen su origen en otro (aliunde originem non trahunt [Lindsay 1991, I.VIII.5]), son veintiuno: determinados, tres (ego, tu, ille); indeterminados, siete (quis, qualis, talis, quantus ['cuán grande'], tantus ['tan grande'], quotus ['cuánto'], totus ['todo']); semideterminados, seis (iste, ipse, hic], is ['aquel'], idem ['el mismo'], sui ['de sí mismo']); y posesivos, cinco (meus, tuus, suus, noster, vester). Los derivados, que son los que derivan de los primitivos (ex istis deducta atque conposita existunt [Lindsay 1991, I.VIII.5]), son todos los demás, como quispiam ('cualquiera') o aliquis ('alguno') ${ }^{10}$.

En la GRAE, desde la edición de 1771 hasta la de 1866 entre los pronombres se enumeran los personales, demostrativos, posesivos, y relativos; desde la de 1867 hasta la de 1916, los personales, demostrativos, posesivos, relativos e indeterminados; y desde la de 1917, los personales, posesivos, correlativos (interrogativos, demostrativos y relativos) e indefinidos. E. Alarcos Llorach puntualiza que los personales tónicos y los indefinidos alguien, algo, nadie, nada y quienquiera siempre son pronombres; las formas tradicionalmente incluidas entre los demostrativos, posesivos, numerales cardinales y el resto de los indefinidos son adjetivos del tipo II susceptibles de experimentar la sustantivación; los relativos átonos son transpositores que dentro del segmento transpuesto se comportan además como sustantivos, adjetivos o adverbios, y los relativos tónicos (interrogativos y exclamativos), cuando actúan como transpositores, transponen una primitiva oración, en cuyo interior funcionan como sustantivos, adjetivos o adverbios, a la categoría del sustantivo ( $C f$. J. Sánchez Lobato - A. Hernando García-Cervigón 2010, pp.82-84; y A. Hernando García-Cervigón 2011).

\footnotetext{
${ }^{10}$ Como hace notar L. Kukenheim, «il n'y a rien de plus compliqué, rien de plus indécis, rien de moins complet que les chapitres consacrés aux pronoms» (1974, p.128). En la gramática española, A. Ramajo Caño considera que «la complejidad estriba en algunas terminologías que hoy nos resultan confusas. Pero, si tenemos presente la tradición gramatical, podemos encontrar una aceptable claridad en la exposición y explicación que del pronombre hacían nuestros gramáticos» (1987, p.127).
} 


\section{EL VERBO}

4.1. En el verbo, lo primero que plantea Isidoro de Sevilla es la cuestión de la etimología del término, que, a su juicio, reside en que, al batir el aire, suena, o bien en que es la parte que más revierte en la oración (Verbum dictum eo, quod verberato aere sonat, vel quod haec pars frequenter in oratione versetur (Lindsay 1991, I.IX.1). Según A. Ramajo Caño, «inmediatamente después de la definición del verbo, los gramáticos han gustado exponer la etimología de esta parte de la oración» (1987, p.175). Sergio, concretamente, comenta:

verbum dictum est eo, quod verberato aere motu linguae haec pars orationis inventa sit, et licet omnes orationes cum hac oratione misceantur, tamen speciale sibi haec pars hoc nomen efficit eo, quod hac frequenter utamur in elocutione, in tantum ut dicamus verba fecit apud populum Tullius, verba fecit Tullius in senatu (Keil 1981, IV, p.405).

Aclarado este punto, Isidoro de Sevilla afirma que con las palabras, que son imágenes del pensamiento, los hombres, al hablar, exteriorizan sus ideas. Del mismo modo que el nombre indica la persona, el verbo señala lo hecho o dicho por esa persona, pudiendo ser su significado con respecto a ella activo o pasivo (In persona verbi agentis et patientis significatio est [Lindsay 1991, I.IX.1]), lo que se observa, por ejemplo en scribo ('yo escribo'), donde se indica el hecho de una persona agente, frente a scribor ('yo soy inscrito'), en que se denota el de una persona que padece la acción.

El doble significado activo / pasivo que puede expresar el verbo aparece en la última parte de la definición de Dionisio de Tracia (la palabra, carente de caso, portadora de los accidentes de tiempo, persona y número, que significa acción o pasión

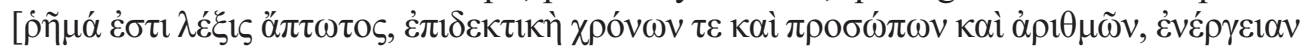

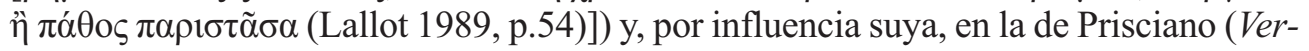
bum est pars orationis cum temporibus et modis, sine casu, agendi vel patiendi significativa [Keil 1981, II, p.369]), cuyas palabras recoge Nebrija en las Introductiones añadiendo el término declinabilis (Pars orationis declinabilis cum modis et temporibus sine casu agendi vel patiendi significativa $[1525$, fol.L]).

4.2. El término verbo tiene dos acepciones, la de los gramáticos y la de los rétores. Desde la perspectiva gramatical, el verbo cuenta con tres tiempos, pretérito, presente y futuro (Grammaticorum in tria cadunt tempora: praeteritum, instans, futurum [Lindsay 1991, I.IX.2]), según se advierte en fecit, facit y faciet, los tres tiempos primarios reconocidos por Dionisio de Tracia y los gramáticos en general. En la acepción retórica, el vocablo verbo se utiliza para hacer referencia a un discurso completo (Rhetorum autem universa oratio verba dicuntur veluti [Lindsay 1991, I.IX.2]), como cuando se dice verbis bonis nos cepit ('su grato verbo nos cautivó') o verba bona habuit ('utilizó un verbo ameno').

Dionisio de Tracia, tras indicar que hay tres tiempos, presente, pasado, futuro

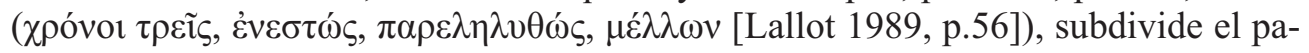
sado en cuatro variantes, el imperfecto, el perfecto, el pluscuamperfecto y el aoristo

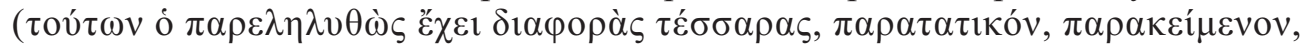




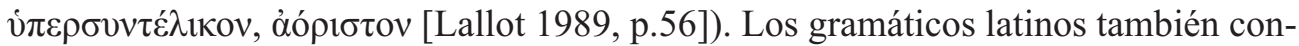
sideraban que existen tres tiempos primarios y que el pasado se subdivide en pretérito imperfecto, pretérito perfecto y pretérito pluscuamperfecto. Así, Donato explica:

tempora verbis accidunt tria, praesens, praeteritum et futurum: praesens, ut lego; praeteritum, ut legi; futurum, ut legam. Sed praeteriti temporis differentiae sun tres, inperfecta, perfecta, plusquamperfecta: inperfecta, ut legebam; perfecta, ut legi; plusquamperfecta, ut legeram. Ergo in modis verborum quinque tempora numerebimus, praesens, praeteritum inperfectum, prateritum perfectum, praeteritum plusquamperfectum, futurum (Keil 1981, IV, p.384).

Este criterio se mantiene al principio entre los gramáticos españoles, si bien Nebrija en las Introductiones distingue los futuros imperfecto y perfecto, con lo que llega a reconocer seis tiempos (Tempora verborum sex sunt. Praesens, praeteritum imperfectum, praeteritum perfectum, praeteritum plusquamperfectum, et futurum imperfectum, et futurum perfectum $[1525$, fol.XV]).

4.3. Las formas, que se llaman así porque informan acerca de cada cosa en particular (quod nos ad unamquamque rem informent [Lindsay 1991, I.IX.3]), ponen de manifiesto qué es lo que se está haciendo (Per has enim ostendimus quid agamus [Lindsay 1991, I.IX.3]), es decir, lo que hoy denominamos modo de acción. De esta manera, la forma meditativa indica que alguien proyecta hacer algo (lecturio ['quiero leer']); la incoativa, que la acción está comenzando (calesco ['estoy entrando en calor']); y la frecuentativa, que la acción se realiza con frecuencia (lectito ['leo a menudo'] ${ }^{11}$. Las formas, como se ve, son portadoras de sentido (sensum tenent [Lindsay 1991, I.IX.3]); sin embargo, los modos comprenden la flexión. De las formas dice Sergio: sensum habent, non declinationem, ut modi. Nam modi declinationes habent et ideo quasi casus verborum sunt (Keil 1981, IV, p.505).

4.4. Los modos indican cómo son sus significados (quemadmodum sint in suis significationibus [Lindsay 1991, I.IX.4]). El indicativo expresa objetivamente una acción (significationem habet indicantis [Lindsay 1991, I.IX.4]) (lego); el imperativo muestra el tono imperioso de quien emite una orden (sonum habet inperantis [Lindsay 1991, I.IX.4]) (lege); el optativo manifiesta el deseo de que se produzca una acción (per ipsum aliquid agere optamus [Lindsay 1991, I.IX.4]) (utinam legerem); el conjuntivo, de acuerdo con su denominación, necesita que se le añada algo para que el sentido del enunciado sea completo (ei coniungitur aliquid, ut locutio plena sit [Lindsay 1991, I.IX.4]) (cum clamem, quare putas quod taceam? ['cuando estoy

${ }^{11}$ Donato y Sergio estudian la forma, junto con el modo, en la cualidad; Prisciano, en la especie; Diomedes emplea los términos cualidad, forma o especie para referirse a los valores del modo de acción; y Probo incluye el género y la cualidad bajo el epígrafe género o cualidad. Con independencia del número de formas reconocidas por los autores latinos, la meditativa de Isidoro de Sevilla se encuentra documentada en Prisciano, Donato, Sergio y Diomedes; la incoativa, en Prisciano, Donato, Sergio, Diomedes y Probo; y la frecuentativa, en Prisciano, Donato, Sergio, Diomedes (que usa el término iterativa) y Probo. 
hablando ¿por qué crees que estoy callado?']); el infinitivo define el tiempo, pero no determina la persona verbal (tempora definiens personam verbi non definit [Lindsay 1991, I.IX.4]) (clamare ['gritar'], clamasse ['haber gritado']), y, si se le añade una persona (clamare debeo, debes, debet ['debo, debes, debe gritar']), se convierte casi en un modo finito (fit quasi finitum [Lindsay 1991, I.IX.4]); y el impersonal carece de la persona del nombre o pronombre (indiget personam nominis vel pronominis [Lindsay 1991, I.IX.4]) (legitur ['se lee']), pero, si se le añade esta, ve completado su sentido (plene sentitur [Lindsay 1991, I.IX.4]) (legitur a me, a te, ab illo ['leo, lees lee']).

Los modos en Isidoro de Sevilla, según se ha podido comprobar, son seis, los

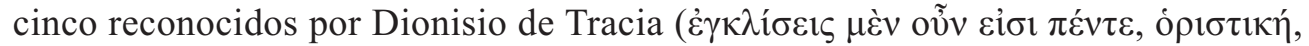

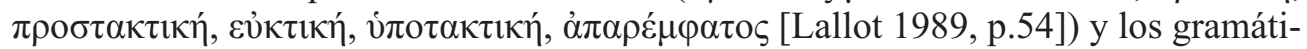
cos latinos Diomedes, Consentio y Prisciano, más el impersonal, registrado en Donato, Sergio, Carisio y Probo. Nebrija, del mismo modo que Prisciano, enumera cinco en las Introductiones (Modi verborum quinque sunt. Indicativus, imperativus, optativus, subiunctivus, infinitivus [1525, fol.XV]), criterio que seguirá la mayor parte de los gramáticos del Siglo de Oro.

4.5. Por lo que respecta a la conjugación, destaca el autor que por medio de ella se conjuntan en una síntesis muchas generalidades (per eam ad unum sonum multa coniungantur [Lindsay 1991, I.IX.5]), de manera que, por ejemplo, al fijarse en qué sílaba termina un futuro, se evita que alguien pueda decir por ignorancia legebo en lugar de legam ('leeré'), ya que la primera y segunda conjugaciones tienen su futuro en - bo y -bor, mientras que la tercera lo hace en -am y -ar, de donde se desprende que, sin declararlo explícitamente, reconoce tres, como la práctica totalidad de los gramáticos latinos, salvo Carisio, que distingue cuatro. Acerca de este particular comenta Sergio: coniugationes verborum sunt tres, prima, secunda, tertia: prima quae a habet secunda persona, secunda quae e, tertia quae i. Ubi invenitur coniugatio? Indicativo modo in numero singulari secunda persona vel ante litteram vel ante syllabam (Keil 1981, IV, p.506).

4.6. Los géneros, término relacionado con 'generar' (quia gignant [Lindsay 1991, I.IX.7]) -como cuando a un verbo activo se le añade una $-r$ y se lo transforma en pasivo, o a un verbo pasivo se le suprime la $-r$ y se lo convierte en activo-, pueden ser activos, los que expresan acción (verbero ['golpeo']); pasivos, los que denotan pasión (verberor ['soy golpeado']); neutros, los que los que no significan ni acción ni pasión (sedeo ['estoy sentado']); comunes, los que indican al mismo tiempo acción y pasión (amplector ['me abrazo' = 'abrazo' + 'soy abrazado']); y deponentes, los que se despojan de su significación pasiva en el participio de futuro terminado en -dus (gloriandus ['el que ha de glorificar']).

Las cinco clases de géneros apuntadas por Isidoro de Sevilla son las que distinguen la mayor parte de los gramáticos latinos, entre ellos Donato, quien afirma: genera verborum, quae ab aliis significationes dicuntur, sunt quinque, activa, passiva, neutra, deponentia, communia (Keil 1981, IV, p.383), y Sergio, que explica: 
omnia verba, sive activa sive passiva sive neutralia sive communia sive deponentia, duas significationes habent, activam et passivam. Nam si neutrum sit, activam habet significationem aut passivam; et si commune sit, utique utramque significationem habet; et si deponens sit, passivam habet declinationem, sed activae significationis est (Keil 1981, IV, p.507).

Nebrija, en las Introductiones, se sitúa en la misma línea (Genera verborum quot sunt? Quinque. Activum, passivum, neutrum, commune, deponens [1525, fol.L]).

\section{OTRAS PARTES}

5.1. El adverbio presenta como característica fundamental ir unido al verbo, como en bene legit ('lee bien'), donde el adverbio bene aparece junto al verbo legit. Por este motivo recibe el nombre de adverbio (Inde ergo dictum adverbium, quod semper verbo iunctum adinpleatur [Lindsay 1991, I.X]). El verbo por sí solo tiene sentido completo (Verbum enim solum sensum inplet [Lindsay 1991, I.X]) (scribo ['escribo']); sin embargo, el adverbio sin el verbo no tiene significado completo (Adverbium autem sine verbo non habet plenam significationem [Lindsay 1991, I.X]) (hodie ['hoy']). Por tanto, para que el adverbio tenga sentido completo, es necesario que se le una un verbo (hodie scribo ['hoy escribo']).

De Dinisio de Tracia procede la idea de que el adverbio es una parte indeclinable

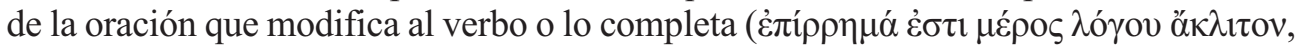

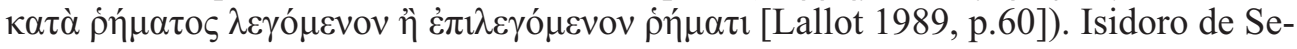
villa sigue a Sergio, quien puntualiza:

adverbium dictum est, quia semper verbo cohaeret, non quod verbum ipsi adverbio cohaereat, sed quod adverbium semper verbo iungatur. Potest enim fieri ut verbum sine adverbio positum intelligatur, Cicero dixit, Cicero fecit. Adverbia sine verbis non habent intellectum: hodie, quid hodie? Non intelligitur, nisi addideris lego, facio aut aliquod verbum, ut hodie lego, hodie facio. Ideo ergo dicta sunt adverbia, quod sola sensum inplere non posunt, sed iuncta verbo inplent sensum (Keil 1981, IV, p.509).

La definición de Donato (Adverbium est pars orationis, quae adiecta verbo significationem eius explanat atque inplet (Keil 1981, IV, p.385) es la fuente de la formulada por Nebrija en las Introductiones (Pars orationis indeclinabilis, quae addita verbo significationem eius aut complet ut mutat aut minuit [1525, fol.LVv.]).

F. Sánchez de las Brozas, en la línea iniciada en la Edad Media y continuada por G.C. Escalígero en el siglo XVI, amplía el campo de acción de esta categoría al comprobar que puede unirse, además de al verbo, a otras clases de palabras, que por los ejemplos se observa que son el adjetivo, otro adverbio e incluso el sustantivo (Aduerbium est dictum quasi ad uerbum, quod sit quasi uerborum adiectiuum et modus, ut bene currit. Adiungitur tamen aliis partibus, ut bene doctus, ualde mane, semper deus, semper lenitas [Sánchez Salor - Chaparro Gómez 1995, p.116]), y, a través de los gramáticos filósofos franceses, influye en la concepción tradicional de la gramática española desde que G.M. de Jovellanos, bajo la influencia de estos, ense- 
ñara en 1795 que «el adverbio puede modificar un verbo, un adjetivo ó otro adverbio» (1903, p.112), erigiéndose asimismo en precursor de ciertas corrientes de la lingüística actual ( $C f$. L.A. Hernando Cuadrado 2009, pp.107-113 y 117).

5.2. El participio, como indica su etimología (quasi particapium [Lindsay 1991, I.XI]), al participar de la naturaleza del nombre y del verbo (quod nominis et verbi capiat partes [Lindsay 1991, I.XI]), toma del nombre los géneros y los casos, del verbo los tiempos y el significado, y de ambos el número y la forma. La definición del participio ofrecida por Isidoro de Sevilla presenta una gran similitud con la de Donato (pars orationis partem capiens nominis, partem verbi; nominis genera et casus, verbi tempora et significationes, utriusque numerum et figuram [Keil 1981, IV, p.363]) y la de Sergio (participium dictum est quasi particapium. Partes enim capit et de nomine et de verbo: a nomine habet genera et casus, a verbo tempora et significationes, ab utroque numerum et figuram [Keil 1981, IV, p.513]).

La caracterización de Dionisio de Tracia, quien había manifestado que esta parte de la oración participa de las características del verbo y el nombre al tener los mismos

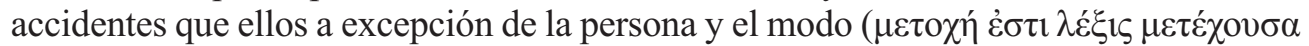

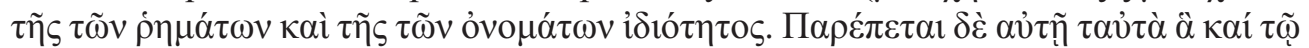

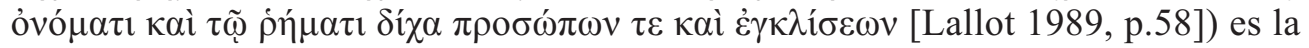
fuente de la de Prisciano (pars orationis, quae pro verbo accipitur, ex quo et derivatur naturaliter, genus et casus habens ad similitudinem nominis et accidentia verbo absque discretione personarum et modorum [Keil 1981, II, pp.548-552]), y esta, a su vez, de la de Nebrija en las Introductiones (Pars orationis declinabilis quae por verbo accipitur ex quo derivatur: Genus et casus habens ad similitudinem nominis, et accidentia verbi sine discretione modorum et personarum [1525, fol.LII]).

5.3 La conjunción une conceptos y oraciones (sensus sententiasque coniungat [Lindsay 1991, I.XII.1]). Por sí sola no tiene ningún valor, pero uniendo unos elementos con otros se presenta como aglutinante del enunciado (quasi quoddam exhibet glutinum [Lindsay 1991, I.XII.1]). Concretamente, une nombres (Augustinus et Hieronymus) o verbos (scribit et legit). La fuerza de todas las conjunciones, tanto si unen (sive copulent [Lindsay 1991, I.XII.1]) como si separan (sive disiungant [Lindsay 1991, I.XII.1]), es una misma (Vna autem vis omnium [Lindsay 1991, I.XII.1]).

La concepción de la conjunción expuesta por Isidoro de Sevilla, al principio, al apuntar que une conceptos y oraciones, guarda relación con la de Sergio (Coniunctio dicta est eo, quod coniungat elocutionem [Keil 1981, IV, p.515]), en la línea de la de Dionisio de Tracia (la conjunción es la palabra que liga un pensamiento con orden y

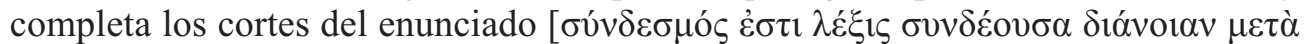

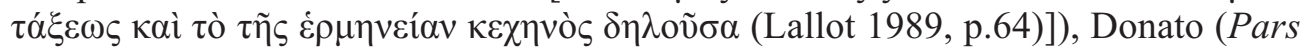
orationis adnectens ordinansque sententiam [Keil 1981, IV, p.364]) y Probo (Pars orationis indeclinabilis nectens ordinansque sententiam [Keil 1981, IV, p.143]); $\sin$ embargo, después, como Prisciano (Coniunctio est pars orationis indeclinabilis, coniunctiva aliarum partium orationis, quibus consignificat, vim vel ordinationem demonstrans [Keil 1981, III, p.93]), acepta que también une palabras. 
La misión de la conjunción, a juicio de F. Sánchez de las Brozas, es unir oraciones, no palabras (Coniunctio non iungit similes casus ut inepte traditur, sed tantum iungit sententias [Sánchez Salor - Chaparro Gómez 1995, p. 118]). Nebrija, que en un pasaje de las Introductiones repite casi literalmente lo expuesto por Donato y Probo (Pars orationis indeclinabilis, connectens ordinansque sententiam [1525, fol.LVII]), en otro lugar de la misma obra, siguiendo a Prisciano, indica que la conjunción sirve también para unir partes de la oración (Coniunctio est quae diuersas partes orationis coniungit [1525, fol.XIIIv.]).

Las conjunciones se clasifican en copulativas, las que unen conceptos o personas (sensum vel personas coniungant [Lindsay 1991, I.XII.2]) (ego et tu eamus ad forum); disyuntivas, las que desunen cosas o personas (disiungunt res aut personas [Lindsay 1991, I.XII.2]) (ego aut tu faciamus); subjuntivas, las que se posponen (subiunguntur [Lindsay 1991, I.XII.2]) (regique hominique Deoque [que = ' $\mathrm{y}$ ']); expletivas, las que completan una proposición (explent propositam rem [Lindsay 1991, I.XII.3]) (si hoc non vis, saltim illud fac ['si no quieres hacer esto, al menos haz eso otro']); comunes, las que se colocan indistintamente delante o detrás (ubivis ponuntur [Lindsay 1991, I.XII.3]) (igitur hoc faciam ['así pues haré esto'] / hoc igitur faciam ['haré, pues, esto']); causales, las que indican la causa por la que se piensa hacer algo (a causa eo, quod aliquid cogitent facere [Lindsay 1991, I.XII.4]) (occido illum, quia habet aurum ['voy a matarlo, porque tiene dinero']); y racionales, las que señalan la razón que se aduce para realizar una acción (a ratione, qua quisque utitur in faciendo [Lindsay 1991, I.XII.4]) (quomodo eum occidam, ne agnoscar: veneno an ferro? [“¿cómo lo mataré para no ser descubierto: con veneno o con un puñal?']).

De estas clases de conjunciones mencionadas por Isidoro de Sevilla, las copulativas, las disyuntivas, las expletivas, las causales y las racionales son las cinco que distingue la mayor parte de los gramáticos latinos en el accidente de la potestas-que Prisciano llama species (species, quam alii potestatem nominant [Keil 1981, III, p.93]), basado en las significationes, término que emplea Sergio (Quinque sunt coniunctionum significationes: sunt enim copulativae, disiunctivae, expletivae, causales, rationales [Keil 1981, IV, p.516])-, y las otras dos, las subjuntivas y las comunes, entran dentro del campo del accidente del ordo. Dionisio de Tracia había clasificado las conjunciones sin adscribirlas a ningún accidente en copulativas, disyuntivas, condicionales, explicativas, causales, dubitativas, ilativas y expletivas $(\tau \tilde{\omega} v \delta \dot{\varepsilon} \sigma v v \delta \delta \dot{\varepsilon} \sigma \mu \omega v$ oi

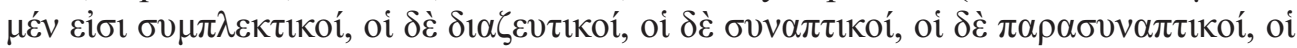

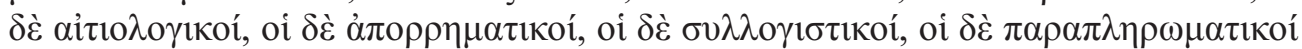
[Lallot 1989, p.64]).

Nebrija, en las Introductiones, en la línea de Prisciano, que había reconocido diecisiete (Species sunt: copulativa, continuativa, subcontinuativa, adiunctiva, causalis, effectiva, approbativa, disiunctiva, subdisiunctiva, disertiva, ablativa, praesumptiva, adversativa, abnegativa, collectiva vel rationalis, dubitativa, completiva [Keil 1981, III, p.93]), enumera nueve especies y cuatro subespecies de una de ellas (copulativa, disiunctiva, subdisiunctiva, causalis [continuativa, subcontinuativa, adiunctiva, effectiva], collectiva, dubitativa, adversativa, approbativa, completiva [1525, 
fols.LVII-LVIIv.]), que en la Gramática reduce a cinco (copulativas, disyuntivas, causales, conclusivas y continuativas [Quilis 1992, p.129]).

5.4. La preposición se llama de esta manera porque se coloca delante de los nombres y los verbos (quod nominibus praeponatur et verbis [Lindsay 1991, I.XIII]). Las preposiciones, según el caso que rijan, pueden ser de acusativo o de ablativo. Las locuelares (loquellares), es decir, las que solo funcionan como prefijos, del tipo de di- o dis-, se encuentran siempre unidas a los verbos (loquellis) creando una palabra nueva (diduco ['deducir']; distraho ['distraer']), por lo que, utilizadas independientes de ellos, no tienen ningún valor.

Los gramáticos latinos inciden en estos aspectos apuntados por Isidoro de Sevi1la. Sergio, que parte de la idea de que praepositio dicitur, quod in loquendo praeponitur (Keil 1981, IV, p.517), anota después que omnes enim praepositiones aut accusativi casus sunt aut ablativi (Keil 1981, IV, p.517) y que loquellares VI sunt, con, di-, dis-, re se am- (Keil 1981, IV, p.517). La preposición, para Dionisio de Tracia, es una parte de la oración que se antepone a todas las demás en composición y en la frase

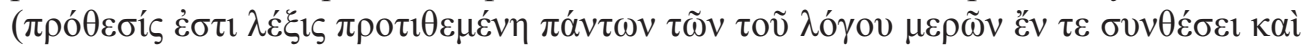

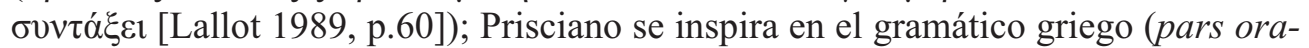
tionis indeclinabilis, quae praeponitur aliis partibus vel appositione vel compositione [Keil 1981, III, p.24]), y Nebrija, en las Introductiones, sigue a este (Pars orationis indeclinabilis, quae aliis partibus orationis praeponitur, aut per compositionem aut per appositionem [1525, fol.LIIIv.]).

5.5. La interjección, interpuesta entre los elementos de la frase, expresa un movimiento afectivo del ánimo (Interiectio vocata, quia sermonibus interiecta, id est interposita, affectum commoti animi exprimit [Lindsay 1991, I.XIV]), como se constata cuando quien se encuentra alegre (exultans) exclama va! ('¡bien!'); quien está triste (dolens), heu! ('¡ay!'); el airado (irascens), hem! ('¡voto a...!'); o el temeroso (timens), ei! ('¡ay de mí!'). Cada lengua posee sus interjecciones propias, que son difíciles de traducir a otras. Donato la define como pars orationis significans mentis affectum voce incondita (Keil 1981, IV, p.366), apunta que solo posee el accidente de la significatio (Interiectioni quid accidit? Tantum significatio [Keil 1981, IV, p.366]), y puntualiza que por él aut laetitiam significamus, ut evax, aut dolorem, ut heu, aut admirationem, ut papae, aut metum, ut attat, et siqua sunt similia (Keil 1981, IV, p.366).

Por su parte, Agustín comenta: rationis est, sed affectio erumpentis animi in vocem, et significat aut laetitiam, ut evax, aut amaritudinem, ut heu, apud Graecos $\varphi \varepsilon v 0$. Ergo quot sunt perturbati animi motus, tot voces reddunt. Et vocantur interiectiones, quod interrumpant orationem (Keil 1981, V, p.524).

F. Sánchez de las Brozas, como Agustín, interpreta que la interjección no es parte de la oración (interiectionem non esse partem orationis [Sánchez Salor - Chaparro Gómez 1995, p.50]), dado que quod naturale est idem est apud omnes; sed gemitus et signa laetitiae idem sunt apud omnes; sunt igitur naturales. Si uero naturales, non sunt partes orationis. Nam eae partes secundum Aristotelem ex instituto non natura debent constare (Sánchez Salor - Chaparro Gómez 1995, p.50). 


\section{CONCLUSIONES}

Isidoro de Sevilla, en el libro primero de las Etymologiae, se ocupa de la gramática, a la que caracteriza, en la línea de los tratadistas latinos, como la ciencia que enseña a hablar correctamente, y el origen y fundamento de las letras liberales, y, en relación con las otras disciplinas del trivium -la retórica y la dialéctica-, como la habilidad en el hablar. El arte gramatical, en el que, de acuerdo con la tendencia de la época, se encuentran incluidos todos los fenómenos lingüísticos y literarios, consta de treinta apartados, ocupando un lugar destacado en él los capítulos dedicados a las partes de la oración.

La oración, como en la tradición grecolatina, es concebida por el arzobispo hispalense con un criterio semántico como una sucesión de palabras con sentido, y dividida en ocho partes (nombre, pronombre, verbo, participio, preposición, adverbio, interjección, conjunción), que, a su juicio, podrían reducirse en realidad a las dos distinguidas por Platón y al principio por Aristóteles, el nombre y el verbo, que expresan, respectivamente, la persona y la acción, constituyendo las restantes meros apéndices de ellas, posición que en el Siglo de Oro adoptará y defenderá F. Sánchez de las Brozas, entre otros.

Sin detenerse a hacer clasificaciones previas como Dionisio de Tracia y los gramáticos latinos, en los que se basa en mayor o menor medida, sobre todo en Donato y Sergio, sino procediendo al tratamiento de los fenómenos in medias res, con un estilo conciso y claro, y un orden riguroso en la exposición de las ideas y los conceptos, en todo momento se percibe su criterio personal, una de cuyas aportaciones más relevantes a la historia de la gramática es el sutil tratamiento dado a la variatio rhetorica en la teoría de la sustitución del pronombre, fenómeno en el que había reparado por primera vez Sergio.

\section{REFERENCIAS BIBLIOGRÁFICAS}

Alarcos Llorach, E. (1994), Gramática de la lengua española, Madrid, Real Academia Española - Espasa Calpe.

Alonso, A. - HenríQuez Ureña, P. (1971), Gramática Castellana. Segundo curso, 24. a ed., Buenos Aires, Losada.

ArAÑó, M. (1877), Elementos de gramática castellana, Barcelona, Tipografía de J. Inglada.

ARnAUld, A. - LANCElot, C. (1966), Grammaire générale et raisonnée, Stuttgart-Bad Cannstatt, F.F. Verlag.

Bürsgens, W. (2003), Flavius Magnus Aurelius Cassiodorus. Institutiones divinarum et saecularium litterarum $=$ Einführung in die geistlichen und weltlichen wissenschaften . Übersetzt und eingeleitet von W. Bürsgens, Friburgo, Herder.

Cossío, J.M. (1959), Marcelino Menéndez y Pelayo. San Isidoro, Cervantes y otros estudios. Selección y nota preliminar de J.M. ${ }^{a}$ de Cossio, $4 .^{\text {a }}$ ed., Madrid, Espasa-Calpe.

Fontaine, J. (1959), Isidore de Seville et la culture classique dans l'Espagne wisigothique, París, Études Augustiniennes. 
Hernando CuAdrado, L.A. (2009), «La teoría del Brocense sobre el adverbio en el contexto de la tradición gramatical», El Humanismo Extremeño, VI, Trujillo, Real Academia de Extremadura de las Letras y las Artes, pp.105-119.

Hernando GarcíA-Cervigón, A. (2011), «La doctrina gramatical de Pedro Felipe Monlau sobre las partes de la oración», Boletín de la Real Academia Española, tomo XCI, cuaderno CCCIII, pp.73-111.

Holtz, L. (2006), «Le De grammatica des Étymologies d'Isidore de Séville, structure générale et traitement des sources», en NAscimento, A.A - AlberTo, P.F. (coords.), IV Congresso Internacional de Latim Medieval Hispânico, Lisboa, Centro de Estudos Clássicos, pp.55-68.

Jovellanos, G.M. (1903), Curso de humanidades castellanas, en Biblioteca de Autores Españoles, XLVI. Obras publicadas e inéditas de D. Gaspar Melchor de Jovellanos. Colección hecha e ilustrada por D. Cándido Nocedal, I, Madrid, Imprenta de Perlado, Páez y Compañía (Sucesores de Hernando), pp.101-155.

KeIL, H. (1981), Grammatici latini, Hildesheim, G. Olms.

Kunenheim, L. (1974), Contributions à L'Histoire de la Grammaire Italienne, Espagnole et Française á l'epoque de la Renaissance, Utrecht, H\&S Publishers.

Lallot, J. (1989), La grammaire de Denys le Thrace, París, Éditions du Centre National de la Recherche Scientifique.

LINDSAY, W.M. (1991), Isidori hispalensis episcopi Etymologiarum sive originum libri XX. Recognovit brevique adnotatione critica instruxit W.M. Lindsay, Oxford University Press.

Marshall, P.K. (1968), Aulus Gellius. Noctes Atticae. Recognovit brevique adnotatione critica instruxit, Oxford, Typographeo Clarendoniano.

Mata y AraúJo, L. de (1805), Nuevo epítome de gramática castellana, Madrid, Imprenta de la Administración del Real Arbitrio de la Beneficencia.

Nebrija, A. de (1525), Introductiones in latinam grammaticen, Alcalá de Henares, M. de Eguia.

Oroz Reta, J. - Marcos Casquero, M.A. (1982-1983), San Isidoro de Sevilla. Etimologías. Edición bilingüe. Texto latino, versión española, notas e índices por J. Oroz Reta y M.A. Marcos Casquero; introducción general por M.C. Díaz y Díaz, Madrid, Biblioteca de Autores Cristianos.

Quilis, A. (1992), Antonio de Nebrija. Gramática de la lengua castellana. Edición de A. Quilis. Madrid, Ediciones de Cultura Hispánica.

RAmajo CAÑo, A. (1987), Las gramáticas de la lengua castellana desde Nebrija a Correas, Ediciones Universidad de Salamanca.

Real Academia Española (1771), Gramática de la lengua castellana, Madrid, Por D. J. de Ibarra, Impresor de Cámara de S.M.

REAl ACADEMia EsPañola (1796), Gramática de la lengua castellana, Madrid, Por la Viuda de D. J. Ibarra, Impresora de la Real Academia.

Real Academia Española (1866), Gramática de la lengua castellana, Madrid, Imprenta Nacional.

Real ACADEmia Española (1867), Gramática de la lengua castellana, Madrid, Imprenta de M. Ginesta.

Real ACAdEMia EsPañola (1870), Gramática de la lengua castellana, Madrid, Imprenta y estereotipia de M. Rivadeneyra. 
Real Academia Española (1916), Gramática de la lengua castellana, Madrid, Perlado, Páez y Compañía (Sucesores de Hernando), Impresores y Libreros de la Real Academia Española.

Real Academia Española (1917), Gramática de la lengua castellana, Madrid, Perlado, Páez y Compañía (Sucesores de Hernando), Impresores y Libreros de la Real Academia Española.

Real ACAdemia Española (1962), Gramática de la lengua española. Nueva edición, reformada, de 1931, y apéndice con las Nuevas Normas de Prosodia y Ortografía declaradas de aplicación preceptiva desde $1^{\circ}$ de enero de 1959, Madrid, Espasa Calpe.

Real ACAdEMia Española (1973), Esbozo de una nueva gramática de la lengua española, Madrid, Espasa Calpe.

Real Academia Española (2001), Diccionario de la lengua española, 22. ${ }^{\text {a }}$ ed., Madrid, Espasa Calpe.

ReIFFerscheId, A. (ed.) (1860), C. Suetonii Tranquilli praeter Caesarum libros reliquae, Leipzig, Sumptibus et formis B.G. Teubneri.

Robins, R.H. (1992), Breve historia de la Lingüistica, 6. ${ }^{\mathrm{a}}$ ed., Madrid, Paraninfo.

SÁnchez DoBlas, J. (1902), Lecciones de gramática castellana para el uso de los alumnos de segunda enseñanza, Palma de Mallorca, B. Rotger.

SÁnchez lobato, J. - Hernando García-Cervigón, A. (2010), Esbozo y Gramática de la lengua española de Emilio Alarcos. Análisis de dos proyectos de gramática académica, Madrid, Editorial Complutense.

SÁnchez Salor, E. - Chaparro Gómez, C. (1995), Francisco Sánchez de las Brozas. Minerva o De causis linguae latinae. Introducción y edición de E. Sánchez Salor (Libri I, III y IV); edición de C. Chaparro Gómez (Liber II), Cáceres, Institución Cultural «El Brocense» Excma. Diputación Provincial de Cáceres - Universidad de Extremadura.

SAn Pedro, P. B. de (1769), Arte del romance castellano, Valencia, Imprenta de B. Monfort. SCALIGER, I.C. (1540), De causis linguae latinae, Lyon, Apud S. Gryphium.

Trujillo, R. (1988), Andrés Bello. Gramática de la lengua castellana destinada al uso de los americanos. Con las Notas de R. J. Cuervo. Estudio y edición de R. Trujillo, Madrid, Arco/Libros.

UhLIG, G. (1965), Grammatici graeci, Hildesheim, G. Olms. 